\title{
Insights into kiwifruit bud rot
}

\author{
M.S. Kabir ${ }^{1}$, B.E. Parry ${ }^{1}$, J.L. Tyson ${ }^{2}$ and M.A. Manning ${ }^{2}$ \\ ${ }^{1}$ The New Zealand Institute for Plant \& Food Research Limited, 412 No 1 Road, RD 2 Te Puke 3182, \\ New Zealand \\ ${ }^{2}$ The New Zealand Institute for Plant \& Food Research Limited, Private Bag 92169, Auckland, 1142, \\ New Zealand \\ Corresponding author: shahjahan.kabir@plantandfood.co.nz
}

Bud rot caused by Pseudomonas syringae pv. actinidiae biovar 3 (Psa) is a severe issue for the kiwifruit industry in New Zealand, particularly within green-fleshed cultivars. Successful management of this disease requires a detailed understanding of the disease cycle, such as identifying when and where Psa is present in/on winter- and flower-buds, the timing of bud-rot initiation, incidence and progression, and any varietal/seasonal/environmental differences. Relevant data is being collected on two greenfleshed cultivars: Actinidia chinensis var. deliciosa 'Hayward' and A. chinensis var. chinensis $\mathrm{x}$ A. chinensis var. deliciosa 'Zesh004' (commonly known as Green14), at four sites where bud rot had been noticed previously. Winter buds are sampled fortnightly and flower buds are sampled weekly from each site. Results from the first year, 2016, indicate that bud-rot incidence was higher in 'Hayward' than in Green14. Psa was detected in dormant and sprouted winter buds but its presence was inconsistent. Psa was detected in all parts of dissected flower buds, with the highest incidence in sepals, then in stalks, and gradually lower detection rates in petals, anthers and ovaries respectively.

\section{Performance of Advance Gold budbreak enhancer on Gold3 kiwifruit in cold and warm seasons}

\author{
C. Molloy, M. Guy, A. Wells and S. McKennie \\ Zelam Limited, P.O. Box 7142, Fitzroy, New Plymouth 4341, New Zealand
}

Advance Gold (AG) is a new agricultural compounds \& veterinary medicines (ACVM)-registered budbreak enhancer for Gold3 kiwifruit. It contains salicylic acid as the active ingredient, and is used in conjunction with nitrogen and calcium salts. Gold3 kiwifruit blocks in the Bay of Plenty up to 1 ha in area were sprayed using convention air blast sprayers fitted with air inclusion nozzles in August of 2015 and 2016, and monitored for budbreak, flowering and components of yield. Following good winter chill in 2015, a block at near sea level produced about 2 king flowers per winter bud (KF/WB) without AG treatment and about $3 \mathrm{KF} / \mathrm{WB}$ following AG treatment. A site at $93 \mathrm{~m}$ above sea level produced a larger number of flowers unassisted and a modest increase following AG treatment. Minimal winter chill in 2016 resulted in very low flower numbers in untreated canes at both sites, with AG treatment producing an increase of approximately $1 \mathrm{KF} / \mathrm{WB}$. The current budbreaker used by the kiwifruit industry, hydrogen cyanamide, produced comparable increases in flower numbers to AG in the four trials but gave a larger proportion of "star triples", tightly clustered triple flowers. Components of yield are presented. 